\title{
Papillary thyroid carcinoma: an update
}

\author{
Virginia A LiVolsi \\ Department of Pathology and Laboratory Medicine, University of Pennsylvania, Philadelphia, PA, USA
}

\begin{abstract}
The past two decades have seen numerous developments in the understanding of the origins and biology of papillary thyroid carcinoma. Advances in molecular biology, clinicopathologic studies of new entities, facility with fine-needle aspiration biopsy, and new radiologic imaging techniques have allowed for earlier diagnosis of these tumors. However, these advances have also caused controversies in cytologic and histopathologic diagnoses as well as therapy decisions. This paper will focus on several pathologic aspects of papillary carcinoma, which impact on its biology and prognosis.

Modern Pathology (2011) 24, S1-S9; doi:10.1038/modpathol.2010.129
\end{abstract}

Keywords: papillary carcinoma; prognostic factors; subtypes; thyroid

\section{Overview of papillary thyroid carcinoma; what everyone needs to know}

\section{Introduction}

This review will cover clinical and pathological aspects of papillary carcinoma and its major variants. Emphasis will be placed on diagnostic features and prognostic factors.

\section{Clinical Aspects}

In the United States, thyroid carcinoma comprises about $1 \%$ of all cancers and accounts for $0.2 \%$ of cancer deaths. ${ }^{1,2}$ Most of these cancers are of the papillary type. This is the most common malignant tumor of the gland in countries having iodinesufficient or iodine-excess diets, and comprises about $80-85 \%$ of thyroid malignancies. These common tumors tend to be biologically indolent and have an excellent prognosis (survival rates of $>95 \%$ at 25 years). Papillary carcinoma can occur at any age and rarely has been diagnosed as a congenital tumor. Most tumors are diagnosed in patients in the third to fifth decades of life. Women are affected more frequently than men in ratios of $2: 1$ to $4: 1 .^{3-6}$

Papillary carcinoma can occur in children, although most series include individuals who are

Correspondence: Dr VA LiVolsi, MD, Department of Pathology and Laboratory Medicine, University of Pennsylvania, 3400 Spruce Street, Sixth Floor, Founders Pavilion, Room 6039, Philadelphia, PA 19104, USA.

E-mail: linus@mail.med.upenn.edu

Received 4 June 2010; accepted 9 June 2010 teenagers in this group. There are certain distinctive histopathologic appearances in young patients, which are rarely seen in adults (these are reviewed below).

The epidemiology of papillary thyroid carcinoma has evoked much interest. Studies from different regions of the world have compared incidences of this tumor from populations living in mountainous areas of the world vs people living near or at sea level. Dietary iodine concentrations appear to influence the incidence, and in some cases, the morphology of the papillary carcinomas. ${ }^{7}$

Perhaps the most important relationship in regard to the etiology of papillary thyroid cancer is the association with radiation. ${ }^{8}$ In the middle part of the last century, thyroid carcinomas were diagnosed frequently in individuals who had been treated with low-dose radiation to the head and neck for benign disease (hemangiomas, lymphangiomas, enlarged thymus, enlarged tonsils, and adenoids). ${ }^{9,10}$ Subsequent to these reports, thyroid cancers (usually papillary) were recognized in survivors of the atomic bomb attacks on Japan at the end of World War II. ${ }^{11,12}$ Later, unusual thyroid tumors occurring in subjects living in areas near underground and/or underwater as well as above ground nuclear bomb tests were noted. ${ }^{13,14}$

In the last quarter of the twentieth century with the increasing use of radiation therapy, survivors of cancers of various organs whose tumor had been treated with radiation were found to develop papillary thyroid cancers as 'second primaries.'15 These were in part attributed to the fact that radiation to the neck damaged the thyroid follicles and caused relative hypothyroidism; appropriate physiological responses to this decline in function included increased secretion of pituitary 
thyrotropin (TSH). It has been speculated that TSH stimulation of damaged follicular epithelium (breaks in DNA leading to mutations and translocations) was causing neoplastic transformation of the thyroid cells (of course, the possibility that these individuals had underlying subtle genetic defects, which predisposed them to the development of multiple neoplasms, must also be considered).

Finally, the episode of the explosion and fire at the nuclear power plant in Chernobyl in the former USSR in April 1986 was followed by what is now known as an 'epidemic' of thyroid carcinoma especially in children under age 15 years at the time of the accident, some of whom were in utero. ${ }^{16-19}$ The availability of biosamples from many of these patients has been coordinated through an international effort (the Chernobyl Tissue Bank); nucleic acids from tumor tissues, uninvolved thyroid, metastases, and blood have been distributed to many laboratories throughout the world in efforts to understand at the molecular and proteomic level the development of thyroid cancer and radiation carcinogenesis in general. ${ }^{20}$ These ongoing studies have produced important, but sometimes controversial, results; however, the Chernobyl accident has engendered many projects involving the pathology of thyroid carcinoma, especially papillary subtypes. (Indeed, the international effort included the appointment of an international panel of thyroid pathologists to examine and render consensus diagnoses on the cases of thyroid cancer occurring in the exposed populations ${ }^{20,21}$.)

The rest of this review will focus on pathologic aspects of papillary thyroid carcinoma in general, the common important subtypes and their clinicopathologic, molecular, and epidemiologic correlates.

\section{Pathology}

The gross appearance of papillary thyroid cancer is quite variable. The lesions may appear anywhere within the gland. By definition, typical papillary carcinomas often average $2-3 \mathrm{~cm}$, although lesions may be quite large or commonly subcentimeter in size. The lesions are firm and usually white in color with an invasive appearance. Lesional calcification is a common feature. Owing to the extensive sclerosis, the lesion may grossly resemble a scar, especially in small lesions, which tend to be found in a subcapsular location in the gland. In addition, cyst formation may be observed. In fact, some lesions may be rarely almost completely cystic making diagnosis difficult. ${ }^{3,4,22}$

Microscopically, papillary carcinomas share certain features. The neoplastic papillae contain a central core of fibrovascular (occasionally just fibrous) tissue lined by one or occasionally several layers of cells with crowded oval nuclei. ${ }^{3,4,22-26}$

The tumors invade lymphatics leading to multifocal lesions and to regional node metastases.

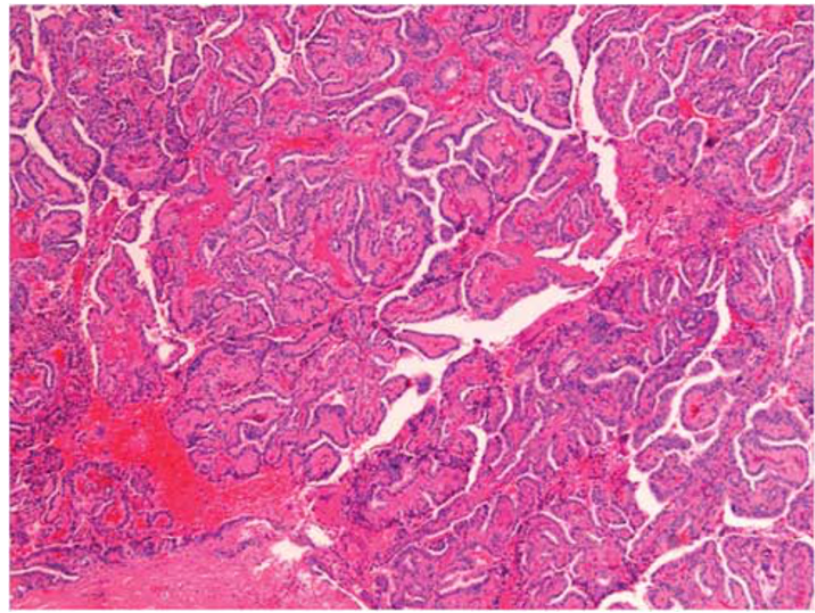

Figure 1 Classic papillary carcinoma is illustrated $(\mathrm{H} \& \mathrm{E} \times 40)$.

Venous invasion rarely occurs and metastases outside the neck are unusual (5-7\% of cases). Some data is available suggesting that this finding alone is predictive of a more aggressive behavior. ${ }^{27}$

Whether the lymphatic invasion itself causes the 'multifocality' by intraglandular spread and 'take' in distinct foci within the thyroid or whether these foci represent true independent clonal proliferations is still debated. In the author's opinion both can occur.

The author theorizes that those glands with multiple small tumors more often possess multiple independent clones in which the morphology of the different tumor foci is distinct one from the other and is consistent with the concept that these represent different clones.

On the other hand, glands with a large clinical papillary cancer and multiple small intrathyroidal foci are 'lymphatic metastases,' the first mechanism seems more apt. ${ }^{3,4,22,28-30}$

Most of these tumors will be composed predominantly or focally of papillary areas (Figure 1). A large number will contain follicular areas as well. (The presence of follicles does not indicate follicular variant of papillary carcinoma; in my view, the follicular variant of papillary carcinoma must be completely follicular in pattern (see below).) The tumor cells are usually cuboidal or columnar. Clear nuclei are found in over $80 \%$ of such lesions, intranuclear inclusions in about $80-85 \%$, and nuclear grooves are seen in almost all the cases. $^{3,4,26,31-33}$ Mitoses are exceptional in usual papillary carcinoma. Psammoma bodies that represent the 'ghosts' of dead papillae are differentiated from dystrophic calcifications by lamellations. True psammoma bodies are formed by focal areas of infarction of the tips of papillae attracting calcium that is deposited on the dying cells. ${ }^{34,35}$ Another proposed theory invokes the mechanism of intracellular accumulation of calcium by tumor cells that lead to their death and release of the calcium. ${ }^{36}$ Progressive infarction of the papilla and ensuing 
calcium deposition lead to lamellation. Psammoma bodies are usually present within the cores of papillae, in the tumor stroma, or in lymphatic vessels, but not within the neoplastic follicles (colloid). ${ }^{37}$ (The phenomenon of calcification of colloid is most problematic in oncocytic (Hurthle cell) nodules and tumors. Herein, the calcification is not lamellated and conforms to the shape of the colloid. The reason for the association of this type of calcification with oncocytes is not known, but is probably related to abnormal physicochemical properties of the colloid produced by oncocytes ${ }^{37}$.)

The presence of psammoma bodies in a cervical lymph node is evidence of a papillary carcinoma in the thyroid. ${ }^{35}$ Only rarely are psammoma bodies found in the thyroid in benign conditions $(<1 \%$ of these bodies are in benign glands). ${ }^{37}$ (The author always wonders whether these reflect a tiny microcancer that has not been sampled or has involuted.)

Regional lymph node metastases are extremely common (50\% of more) at initial presentation of usual papillary cancer. This feature does not apparently adversely affect long-term prognosis especially in patients under age 45 years at diagnosis. Some patients will present with cervical node enlargement and will have no clinically obvious thyroid tumor. Not infrequently the nodal metastasis will involve one node that may be cystic. Why only one node is involved is not explained. ${ }^{38}$

Distant metastases of papillary carcinoma to lungs and bones occur in $5-7 \%$ of cases. ${ }^{39}$ Despite the presence of multiple metastases, however, survival may still be prolonged, especially if the metastases can be treated with radioiodine. In ordinary papillary carcinoma, death is uncommon.

\section{Nuclear features of papillary carcinoma}

Although the initial diagnostic criterion for the diagnosis of papillary thyroid carcinoma was the presence of papillary growth pattern, in the latter half of the last century, nuclear criteria for the diagnosis became important as well. In the past few decades, the nuclear features have become the diagnostic hallmark of the tumor and growth pattern is of lesser or minimal importance. Indeed, the WHO definition of papillary thyroid carcinoma reflects this. ${ }^{25}$

The nuclei of papillary cancer have been described as clear, ground glass, empty, or Orphan Annie eyed. ${ }^{26,31}$ These nuclei are larger and more oval than normal follicular nuclei and contain hypodense chromatin. In papillary cancer, these nuclei often overlap one another (Figure 2). Although cleared nuclei are characteristic of papillary carcinoma, autoimmune thyroiditis, particularly Hashimoto's disease, often shows similar nuclear changes. ${ }^{40,41}$ Intranuclear inclusions of cytoplasm are often found. Another characteristic of the papillary cancer nucleus is the nuclear
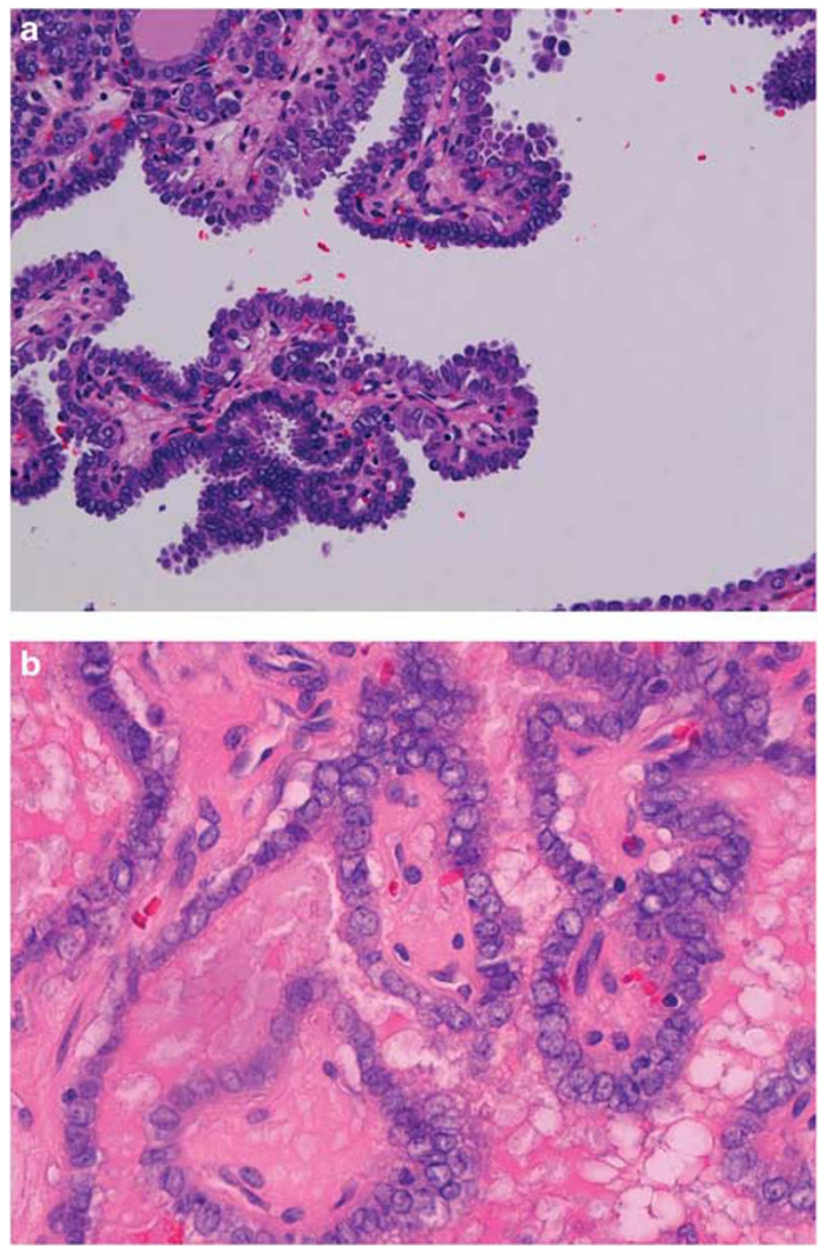

Figure 2 (a) Papillary carcinoma nuclear features $(H \& E \times 20)$. (b) Papillary carcinoma nuclear features are illustrated $(\mathrm{H} \& \mathrm{E} \times 100)$.

groove. Nuclear grooves may be seen in other thyroid lesions including Hashimoto's disease, adenomatous hyperplasia, and diffuse hyperplasia as well as in follicular adenomas (particularly hyalinizing trabecular tumor). ${ }^{25}$

\section{What Makes the Nuclei Like This?}

The answer to that question is not understood. Ultrastructural studies failed to answer the dilemma. In 1998, Fischer et $a l^{42}$ showed that transfecting thyroid cells with ret oncogene produced morphological changes that mimicked those seen in papillary carcinoma. However, this work has not been further elucidated.

Recent work from Italy has shown that immunohistochemical staining for the protein emerin shows distinctly different patterns between papillary carcinoma nuclei and those of normal thyroid or benign conditions. The staining was characteristic in both cytological and histological preparations. This work needs to be reproduced in other laboratories, but 
although it may be clinically useful, it does not explain the curious morphology of the nucleus. ${ }^{43}$

\section{Nuclear Mimics}

Benign conditions of the thyroid can show abnormal nuclear morphology. This is most pronounced in moderate to severe Hashimoto thyroiditis, although similar changes can be found in the glands of patients with Graves' disease and in nodular goiter. In some cases of nodular goiter, the nuclear clearing and inclusions are so pronounced as to be present in every cell. Most thyroid pathologists consider this as an artifact (possible of fixation). The helpful diagnostic clue in these cases is the diffuse nature of the process. If these glands were affected by papillary carcinoma, it would be involving the entire gland without mass lesion effect (that does not happen).

An additional interesting question is why is there an increased incidence of epithelial tumors (usually papillary carcinoma), especially microcarcinomas in Hashimoto disease, an autoimmune process ${ }^{44}$ ? In similar situations in other organs (celiac disease, Sjorgren's syndrome), when tumors arise in affected organs, they are usually malignant lymphomas and epithelial malignancies are rare. In contrast, although malignant lymphoma does arise on the background of Hashimoto disease, it is rare in comparison with the frequency of carcinoma, especially micropapillary tumors, which are often multifocal.

In the other classical autoimmune thyroid disorder (Graves' disease), cancer is rare and lymphoma is very unusual. These situations currently are unexplained.

Although these questions require additional study, the morphology of the nuclei is helpful for establishing the diagnosis of papillary carcinoma. As they are so characteristic, they allow for a cytologic diagnosis of papillary cancer. In the National Cancer Institute categorization, the 'suspicious for cancer' and the unequivocal 'malignant' diagnostic categories are essentially reserved (with few exceptions) for papillary carcinoma. ${ }^{26}$

\section{Prognostic Factors}

Poor prognostic factors in papillary carcinoma include older age at diagnosis, male sex, large tumor size, and extrathyroidal growth. Pathologic variables associated with a more guarded prognosis include less differentiated or solid areas, vascular invasion, and aneuploid cell population. . $^{3,4,37,45,46}$

Whether certain subtypes of papillary carcinoma are in and of themselves associated with more aggressive clinical behavior are unclear. However, at least four subtypes should be mentioned in this regard: tall cell variant, diffuse sclerosis variant, solid variant, and follicular variant.
Tall cell variant

Tall cell variant makes up $10 \%$ of the papillary cancers. The tumor is usually large $(>6 \mathrm{~cm})$, extends extrathyroidally, and shows mitotic activity and vascular invasion more often than classical papillary cancer. The tumor tends to occur in elderly patients. ${ }^{24}$

The tall cell is twice as tall as it is wide and its cytoplasm is often eosinophilic. Tall cells should represent $50 \%$ or more of the papillary carcinoma cells to make the diagnosis of tall cell variant. ${ }^{24,25,47}$ The tumors show an extensive papillary pattern (Figures 3 and 4).

Local recurrences with invasion of the trachea can be seen and this complication may be fatal. Dedifferentiation to squamous cell carcinoma (anaplastic carcinoma) has been described..$^{48}$ (In cases of anaplastic carcinoma, which apparently arise in association with tall cell papillary carcinoma, the presence of hemorrhagic areas with granulation tissue and focal squamous metaplastic foci may be

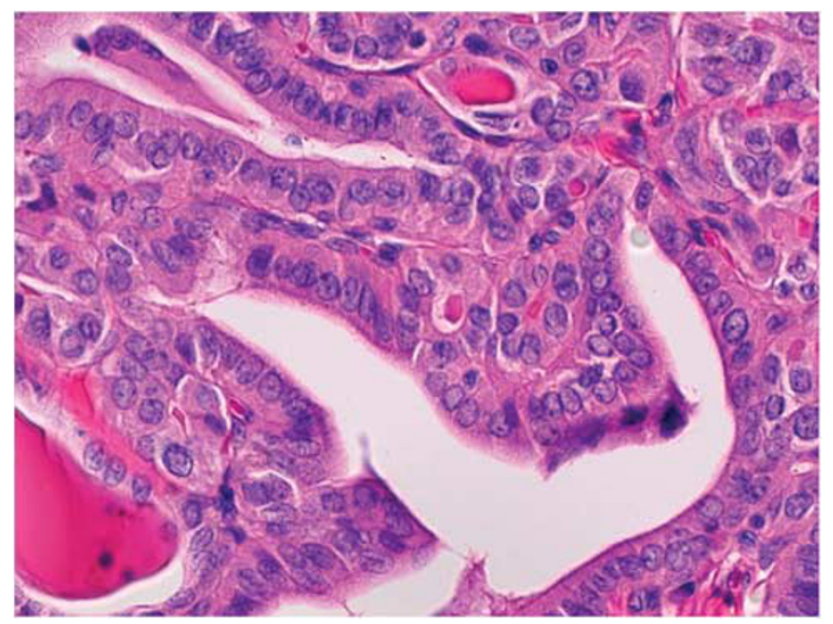

Figure 3 Tall cell variant of papillary carcinoma $(\mathrm{H} \& \mathrm{E} \times 100)$.

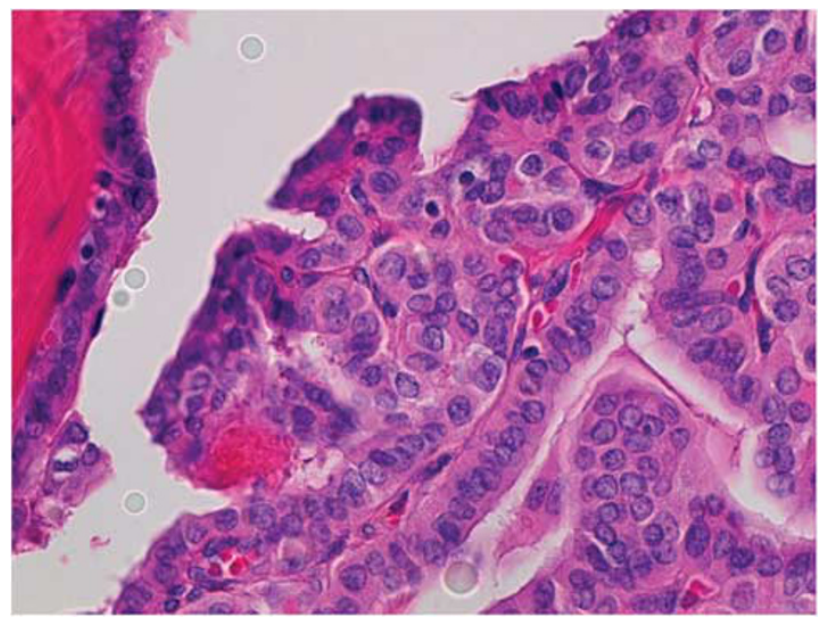

Figure 4 Tall cell variant of papillary carcinoma $(\mathrm{H} \& \mathrm{E} \times 100)$. 
noted in the original tumor. As the length of time between the diagnosis of the primary and the anaplastic tumors is often prolonged (5-10 years), it is considered highly unlikely that these foci of squamous change represent anaplastic carcinoma.)

Flow cytometry studies, although limited in number, have failed to reveal differences between typical papillary carcinoma and the tall cell variant. ${ }^{49}$

The prognosis for this variant is less favorable than for usual papillary cancer (with estimated 10 year survival rates of $75 \%$ ). Although it was believed that the poor outcome in these tumors may be secondary to the fact that these tumors are often associated with poor prognostic variables (older age, extrathyroidal spread, necrosis, and high mitotic rate), the work of Ghossein et $a 5^{50}$ has shown that even tall cell cancers that are contained within the thyroid and that are small can be clinically aggressive.

We have noted ${ }^{51}$ that tall cell microcarcinomas also are associated with a less favorable clinical behavior when compared with usual or follicular variant micropapillary carcinoma. We found in our series that tall cell microcarcinoma was more often extrathyroidal ( $50 \%$ vs $10 \%$ ) lymphovascular invasion $(28 \%$ vs $10 \%)$ and nodal metastases $(36 \%$ vs $10 \%)$ than classical or follicular variant microcarcinoma.

The interesting finding that tall cell papillary carcinoma frequently harbors Braf mutations (and tumors with this molecular signature tend to be aggressive) has been noted from many laboratories. ${ }^{52-55}$ This molecular pattern may be useful in divising targeted therapies for these tumors, which clinically tend to be over-represented in papillary carcinomas that are radioiodine insensitive. ${ }^{52}$ (This topic will be covered elsewhere in this symposium.)

One final note about tall cell variant is that it is frequently not recognized as such, and as a corollary, it has been pathologically confused with other entities-Warthin-like papillary carcinoma, Hurthle cell, or oncocytic nodules and neoplasms. ${ }^{50,56}$ In our dataset of cases of papillary carcinoma referred to our institution, tall cell cytology was noted in only $14 \%$ of the cases we diagnosed as tall cell papillary carcinoma or as papillary carcinoma having tall cell features.

Warthin-like papillary carcinoma (Figure 5) resembles a similar but benign tumor of the salivary gland, and it is always associated with a lymphoplasmacytic infiltrate in the cores of the papillae. It is often soft and cystic and not firm and sclerotic as is tall cell carcinoma. As it is not infrequently of small size and gland confined and in many cases circumscribed, its prognosis is similar to usual papillary carcinoma and not tall cell carcinoma. ${ }^{57,58}$ However, rare cases of Warthin-like papillary carcinoma can show at the infiltrative edges, foci of invasion with loss of lymphoplasmacytic infiltrate and extrathyroidal extension resembling tall cell

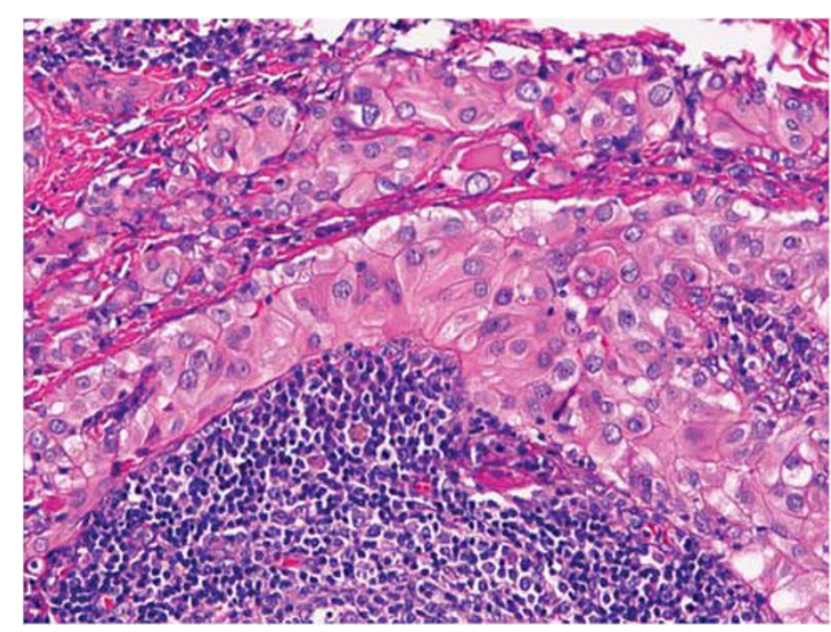

Figure 5 Warthin-like papillary carcinoma $(\mathrm{H} \& \mathrm{E} \times 200)$.

variant papillary carcinoma in these areas. The numbers of such cases and follow-up data are too sparse to indicate what the clinical behavior of these tumors will be.

Nodules and tumors composed of oncocytes or Hurthle cells show growth patterns similar to follicular adenomas/carcinomas-circumscription/ encapsulation and not the infiltrative-type growth of tall cell tumors, which more closely resemble the infiltrative growth of usual papillary thyroid carcinomas. ${ }^{25,37}$

\section{Diffuse sclerosis variant}

The diffuse sclerosis variant of papillary carcinoma represents only about $3 \%$ of all papillary carcinomas. The tumor, which most often affects children and young adults, may present as bilateral goiter. The tumor permeates the gland outlining the intraglandular lymphatics. Tumor papillae have associated areas of squamous metaplasia, which resemble 'morular' metaplasia of the endometrium. Numerous psammoma bodies are found. In fact, plain radiographs of the neck will show the thyroid lymphatics outlined by calcium. Grossly, the tumor is extremely hard reflecting the extensive calcification. Lymphocytic infiltrates are found around the tumor foci; indeed, the background thyroid shows well-developed chronic lymphocytic thyroiditis. Both the histology and immunohistology of the background thyroid are identical to Hashimoto disease. ${ }^{59,60}$ It is unclear if the thyroiditis preceded the tumor or developed as a reaction to the neoplasm.

The lesions are virtually all associated with regional nodal metastases at diagnosis. They often show extracapsular extension, distant, and nodal metastases (almost 100\% will have regional node involvement at presentation) and recur in the neck These tumors have a somewhat more serious prognosis than usual childhood/adolescent papillary cancer ${ }^{61-63}$ and a decreased disease-free survival 


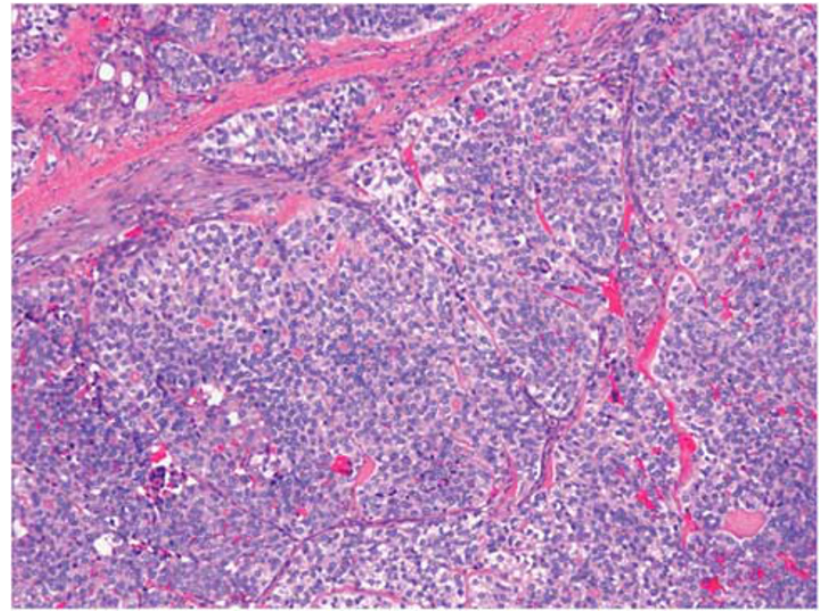

Figure 6 Solid variant of papillary carcinoma $(H \& E \times 100)$.

when compared with the usual-type papillary carcinoma. However, mortality is low. ${ }^{63}$

\section{Solid variant}

A solid growth pattern is noted focally in many papillary carcinomas. When the solid growth represents $>50 \%$ of the tumor mass, a diagnosis of solid variant of papillary carcinoma may be made. The solid variant is most commonly seen in children and has been reported in $>30 \%$ of patients with papillary carcinoma after the Chernobyl nuclear accident. ${ }^{64,65}$ The nuclear features are those of papillary carcinoma, although the nuclei tend to be more rounded than oval.

Although some studies particularly from Japan have considered the solid papillary carcinoma as a poorly differentiated, tumor with a guarded prognosis, in North America and Europe, this has not been found. It is important to recognize these lesions as papillary carcinomas and not over-diagnose them as more aggressive tumors such as poorly differentiated (insular) carcinoma ${ }^{6,67}$ (Figure 6).

Solid variant of papillary carcinoma can be associated with follicular variant and even classic papillary tumor. It has a propensity for not only lymphatic but also venous invasion. ${ }^{6}$

Does this variant occur in adults? Yes, and in the author's experience, over one-third of these arise in patients with systemic autoimmune disease. The interrelationship of these disorders is unknown.

The prognosis of solid variant of papillary cancer is almost as good as classic papillary carcinoma, both in children and in adults. ${ }^{6-69}$ They do not have the guarded prognosis of poorly differentiated carcinoma, even in the presence of necrosis. ${ }^{68}$

\section{Follicular variant of papillary cancer}

The follicular variant of papillary carcinoma is a controversial entity. ${ }^{70-73}$ The incidence of this variant is difficult to determine since in the past some of these lesions have been classified as

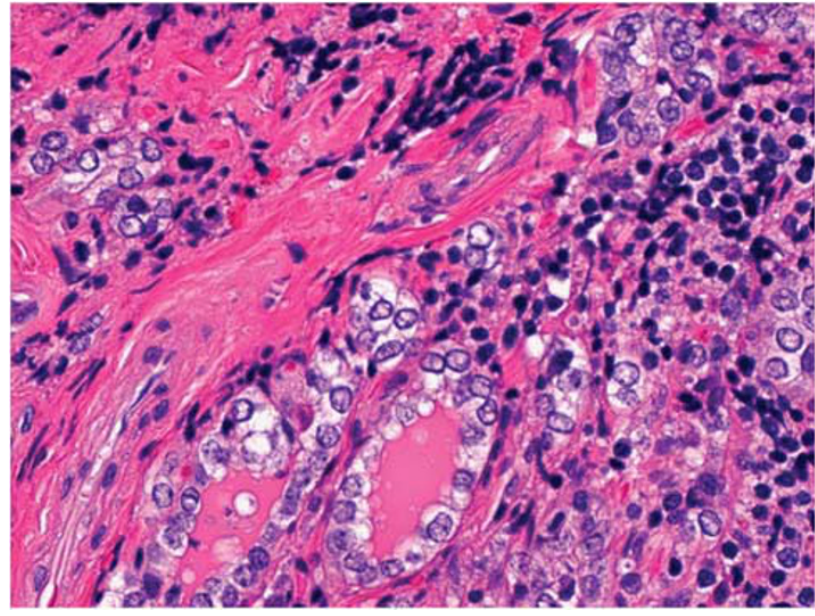

Figure 7 Infiltrative subtype of follicular variant of papillary carcinoma $(\mathrm{H} \& \mathrm{E} \times 100)$.

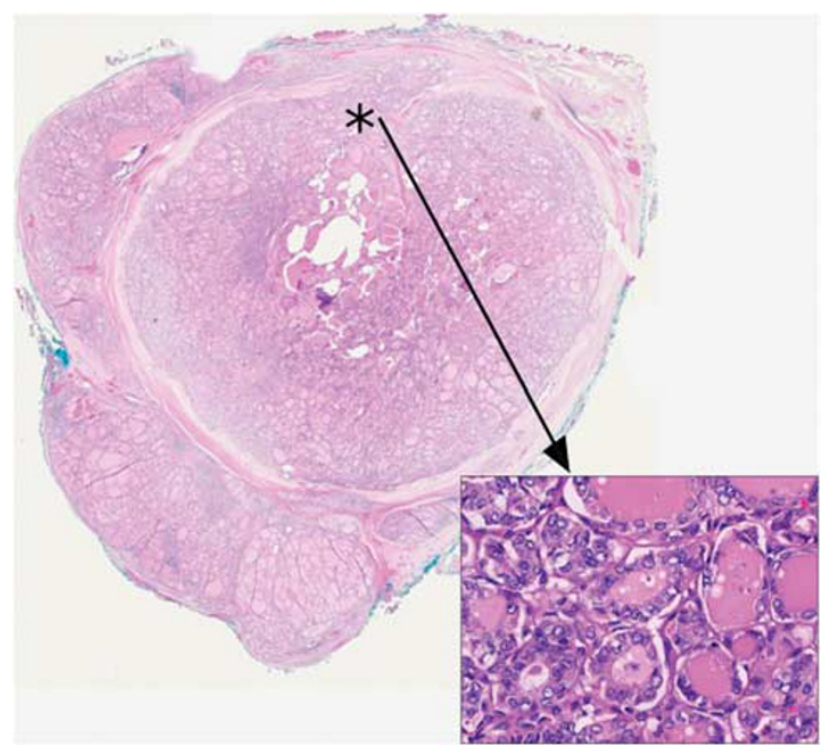

Figure 8 Encapsulated follicular variant of papillary carcinoma $(\mathrm{H} \& \mathrm{E} \times 20)$. *Indicates area of transcapsular invasion. (Inset) Nuclear features are shown $(\mathrm{H} \& \mathrm{E} \times 200)$.

follicular carcinomas or adenomas (or atypical adenomas). The diagnosis of this variant is easy if the nuclear features are characteristic and the growth pattern is noncircumscribed and infiltrative $^{74}$ (Figure 7). However, many of these tumors are circumscribed or even encapsulated; this subtype is diagnosable as a papillary carcinoma if the nuclear features are diffusely present throughout the tumor and characteristic and/or if there is invasion (of capsule and/or of capsular vessels) (Figure 8a).

The cytological diagnosis of these lesions is often difficult as the nuclei of this variant rarely show all of the characteristics of papillary carcinoma; most notably, they rarely contain nuclear grooves. Hence, the cytologist will often render a diagnosis of 'suspicious for malignancy' or 'follicular neoplasm, papillary carcinoma suspected. ${ }^{26}$ It is the author's 
opinion that these are the tumors, which may benefit from intraoperative consultation as it has been the experience in our institution that about 40$50 \%$ of these cases can be diagnosed as papillary carcinoma intraoperatively using both classic frozen section and intraoperative cytological evaluation. ${ }^{75,76}$

The most controversial lesions in the follicular variant of papillary carcinoma group are those that are encapsulated, show no invasion, and/or have multifocal or imperfect nuclear features. ${ }^{74}$ Studies have shown poor diagnostic agreement even among so-called 'expert thyroid pathologists. ${ }^{77-79}$ It has been suggested that these be diagnosed as 'adenomas,' 'atypical adenomas,' or 'tumors of indeterminant malignant potential.' Immunostaining (HBME1 CK 19, galectin-3) or molecular studies for ret/PTC with microdissected samples have not solved the controversy. ${ }^{80-82}$ A very small percentage of these lesions will behave in a clinically aggressive manner and it may be that they are truly cancers, but that they are so slowly growing that conservative treatment is warranted. ${ }^{83}$ The controversy will continue until some 'magic marker' or technique allows for better diagnostic definitions.

A final topic in the follicular variant of papillary carcinoma saga involves the finding of a microfocus $(<1 \mathrm{~cm})$ of papillary carcinoma with classical nuclei (and sometimes even with papilla formation) within an otherwise completely benign follicular adenoma or adenomatous nodule. Some pathologists consider these lesions within the spectrum of atypical adenoma; others prefer to diagnose these as micropapillary carcinoma arising within an adenoma. As these are confined not only within the thyroid, but also within the adenoma, they should be expected to behave as incidental microcarcinomas and should be therapeutically approached as such. ${ }^{3,74}$

\section{Summary}

This paper gave an overview of the pathological issues related to papillary thyroid carcinoma, including an update on nuclei, the benign conditions that may mimic the cancer and the implications of several subtypes of the tumor. The immunohistochemical and molecular evaluations and analyses are covered by other papers in this symposium. The concept of follicular variant of papillary carcinoma is briefly discussed here as it too will be described in other papers from this symposium.

\section{Disclosure/conflict of interest}

The author declares no conflict of interest.

\section{References}

1 Jemal A, Siegel R, Ward E, et al. Cancer statistics, 2009. CA Cancer J 2009;59:225-249.
2 Enewold L, Zhu K, Ron E, et al. Rising thyroid cancer incidence in the United States by demographic and tumor characteristics 1980-2005. Cancer Epiodemiol Biomarkers Prev 2009;18:784-791.

3 Rosai J, Carcangui ML, DeLellis RA. Tumors of the Thyroid Gland. Atlas of Tumor Pathology, Fascicle 5. Armed Forces Institute of Pathology: Washington, DC, 1992.

4 Baloch Z, LiVolsi VA. Pathology of the thyroid gland. In: Livolsi VA, Asa S (eds). Endocrine Pathology. Churchill Livingston: Philadelphia, PA, 2002, pp 61-88.

5 Mazzaferri EL. Long-term outcome of patients with differentiated thyroid carcinoma: effect of therapy. Endocr Pract 2000;6:469-476.

6 Mazzaferri EL, Massoll N. Management of papillary and follicular (differentiated) thyroid cancer: new paradigms using recombinant human thyrotropin. Endocr Relat Cancer 2002;9:227-247.

7 Williams ED, Abrosimov A, Bogdanova T, et al. Morphologic characteristics of Chernobyl-related childhood papillary thyroid carcinomas are independent of radiation exposure but vary with iodine intake. Thyroid 2008;18:847-852.

8 Hunt JL. Radiation induced thyroid diseases. Pathol Case Rev 2009;14:224-230.

9 DeGroot L, Paloyan E. Thyroid carcinoma and radiation: a Chicago epidemic. JAMA 1973;225:487-491.

10 Hempelmann LW, Pifer GW, Burke GJ, et al. Neoplasms in persons treated with $\mathrm{X}$ rays in infancy for thymic enlargement. J Natl Cancer Instit 1967;38:317-341.

11 Wood JW, Tamagaki K, Nerishi SR, et al. Thyroid carcinoma in atomic bomb survivors in Hiroshima and Nasaki. Am J Epidemiol 1969;89:4-14.

12 Nakachi K, Hayashi T, Hamatani K, et al. Sixty years of followup of Hiroshima and Nafgasaki survivors: cancer progress in molecular epidemiology studies. Mutat Res 2008;659:109-117.

13 Takahashi T, Schoemaker MJ, Trott KR, et al. The relationship of thyroid cancer with radiation exposure from nuclear weapon testing in the Marshall Islands. J Epidemiol 2003;12:99-107.

14 Anspaugh LR, Ricker YE, Black SC, et al. Historical estimates of external gamma exposure and collective external gamma exposure from testing at the Nevada Test Site. Health Phys 1990;59:525-532.

15 Chow EJ, Friedman DL, Stovall M, et al. Risk of thyroid dysfunction and subsequent thyroid cancer among survivors of acute lymphoblastic leukemia: a report from the Childhood Cancer Survivor Study. Pediatr Blood Cancer 2009;53:432-437.

16 Becker DV, Robbins J, Beebe GW, et al. Childhood thyroid cancer following the Chernobyl accident: a status report. Endocrinol Metab Clin N Amer 1996;25:197-211.

17 Nikiforov Y, Gnepp DR, Fagin JA. Thyroid lesions in children and adolescents after the Chernobyl disaster: implications for the study of radiation tumorigenesis. J Clin Endocrinol Metab 1996;81:9-14.

18 Tuttle RM, Becker DV. The Chernobyl accident and its consequences: update at the millenium. Sem Nucl Med 2000;30:133-140.

19 Williams D. Radiation carcinogenesis: lessons from Chernobyl. Oncogene 2009;27:S9-S18.

20 Thomas GA, Williams ED. Chernobyl thyroid tumor tissue and nucleic acid bank. Radiat Res 2001;156:333.

21 Thomas GA, Williams ED, Becker DV, et al. Chernobyl tumor bank. Thyroid 2000;10:126-127. 
22 Carcangui ML, Zampi G, Pupi A, et al. Papillary carcinoma of the thyroid: a clinico-pathologic study of 241 cases treated at the University of Florence, Italy. Cancer 1985;55:805-828.

23 Vickery A. Thyroid papillary carcinoma. Pathological and philosophical controversies. Am J Surg Pathol 1983;7:797-807.

24 Hawk W, Hazard J. The many appearances of papillary carcinoma of the thyroid. Cleveland Clin Q 1976;43:207-216.

25 DeLellis RA, Lloyd RV, Heitz PU, et al. WHO Classification of Tumours. Pathology and Genetics of Tumours of Endocrine Organs. IARC, Press: Lyon, 2004.

26 Baloch ZW, LiVolsi VA, Asa SL, et al. Diagnostic terminology and morphologic criteria for cytologic diagnosis of thyroid lesions: a synopsis of the National Cancer Institute Thyroid Fine-Needle Aspiration State of the Science Conference. Diagn Cytopathol 2008;36:425-437.

27 Gardner RE, Tuttle RM, Burman KD. Prognostic importance of vascular invasion in papillary thyroid carcinoma. Arch Otolaryngol Head Neck Surg 2000;126:309-312.

28 Hicks DG, LiVolsi VA, Neidich JA, et al. Clonal analysis of solitary follicular nodules in the thyroid. Am J Pathol 1990;137:553-562.

29 Sugg SL, Ezzat S, Rosen IB, et al. Distinct multiple RET/PTC gene rearrangements in multifocal papillary thyroid neoplasia. J Clin Endocrinol Metab 1998;83:4116-4122.

30 Hunt JL, LiVolsi VA, Baloch ZW, et al. Microscopic papillary thyroid carcinoma compared with clinical carcinomas by loss of heterozygosity mutational profile. Am J Surg Pathol 2003;27:159-166.

31 Hapke MR, Dehner LP. The optically clear nucleus. A reliable sign of papillary carcinoma of the thyroid? Am J Surg Pathol 1979;3:31-38.

32 Deligeorgi-Politi H. Nuclear crease as a cytodiagnostic feature of papillary thyroid carcinoma in fine-needle aspiration biopsies. Diagn Cytopathol 1987;3:307-310.

33 Scopa CD, Melachrinou M, Saradopoulou C, et al. The significance of the grooved nucleus in thyroid lesions. Modern Pathol 1993;6:691-694.

34 Johannessen J, Sobrinho-Simoes M. The origin and significance of thyroid psammoma bodies. Lab Invest 1980;43:287-296.

35 Hunt JL, Barnes EL. Non-tumor-associated psammoma bodies in the thyroid. Am J Clin Pathol 2003;119: 90-94.

36 Das DK. Psammoma body: a product of dystrophic calcification or of a biologically active process that aims at limiting the growth and spread of tumor? Diagn Cytopathol 2009;37:534-541.

37 LiVolsi VA. Surgical Pathology of the Thyroid. WB Saunders Co: Philadelphia, 1990.

38 Maceri D, Babyak J, Ossakow S. Lateral neck mass: sole presenting sign of metastatic thyroid cancer. Arch Otolaryngol Head Neck Surg 1986;112:47-49.

39 Hoie J, Stenwig AE, Kullmann G, et al. Distant metastases in papillary thyroid cancer. A review of 91 patients. Cancer 1988;61:1-6.

40 Hunt JL, Baloch ZW, Barnes L, et al. Loss of heterozygosity mutations of tumor suppressor genes in cytologically atypical areas in chronic lymphocytic thyroiditis. Endocr Pathol 2002;13:321-330.

41 Sargent R, LiVolsi V, Murphy J, et al. BRAF mutation is unusual in chronic lymphocytic thyroiditis-associated papillary thyroid carcinomas and absent in nonneoplastic nuclear atypia of thyroiditis. Endocr Pathol 2006;17:35-41.

42 Fischer AH, Bond JA, Taysavang $\mathrm{P}$, et al. Papillary thyroid carcinoma oncogene (RET/PTC) alters the nuclear envelope and chromatin structure. Am J Pathol 1998;153:1443-1450.

43 Asioli S, Bussolati G. Emerin immunohistochemistry reveals diagnostic features of nuclear membrane arrangement in thyroid lesions. Histopathology 2009;54:571-579.

44 Matos PS, Ferreira AP, Ward LS. Prevalence of papillary microcarcinoma of the thyroid in Brazilian autopsy and surgical series. Endocr Pathol 2006;17:165-173.

45 Joensuu H, Klemi P, Eerola E. DNA aneuploidy in follicular adenomas of the thyroid gland. Am J Pathol 1987;124:373-376.

46 Moreno-Egea A, Rodriquez-Gonzalez M, Sola-Perez J, et al. Multivariate analysis of histopathlogical features as prognostic factors in patients with papillary thyroid carcinoma. Br J Surg 1995;82:1092-1095.

47 Ghossein R, Livolsi VA. Papillary thyroid carcinoma tall cell variant. Thyroid 2008;18:1179-1181.

48 Bronner MP, LiVolsi VA. Spindle cell squamous carcinoma of the thyroid: an unusual anaplastic tumor associated with tall cell papillary cancer. Mod Pathol 1991;4:637-643.

49 Flint A, Davenport R, Lloyd R. The tall cell variant of papillary carcinoma of the thyroid gland. Arch Pathol Lab Med 1991;115:169-171.

50 Ghossein RA, Leboeuf R, Patel KN, et al. Tall cell variant of papillary thyroid carcinoma without extrathyroid extension: biologic behavior and clinical implications. Thyroid 2007;17:655-661.

51 Baloch ZW, Shafique K, Montone K, et al. Does tall cell histology affect the clinical behavior of papillary thyroid microcarcinoma? Lab Invest 2010;90:271A (abstract \# 1217).

52 Rivera M, Ghossein RA, Schoder H, et al. Histopathologic characterization of radioactive iodine-refractory fluorodeoxyglucose-positron emission tomography-positive thyroid carcinoma. Cancer 2008;113:48-56.

53 Nikiforova M, Kimura ET, Gandhi M, et al. BRAF mutations in thyroid tumors are restricted to papillary carcinomas and anaplastic or poorly differentiated carcinomas arising from papillary carcinoma. J Clin Endocrinol Metab 2003;88:5399-5404.

54 Tetzlaff MT, LiVolsi VA, Baloch ZW. Assessing the utility of a mutational assay for B-RAF as an adjunct to conventional fine needle aspiration of the thyroid gland. Adv Anat Pathol 2006;13:228-237.

55 Ugolini C, Agnese P, Basolo F. The role of BRAF V $600 \mathrm{E}$ mutation in the management of thyroid papillary carcinoma. Path Case Rev 2009;14:231-235.

56 Montone KT, Baloch ZW, Shafique K, et al. Tall cell variant of papillary carcinoma and papillary carcinoma with tall cell features are often underdiagnosed: a retrospective analysis of cases referred for second opinion for clinical management. Lab Invest 2010;90:277A (abstract 1241).

57 Apel RL, Asa SL, LiVolsi VA. Papillary Hürthle cell carcinoma with lymphocytic stroma. 'Warthin-like tumor' of the thyroid. Am J Surg Pathol 1995;19: 810-814.

58 Baloch ZW, LiVolsi VA. Fine-needle aspiration cytology of papillary hurthle cell carcinoma with lymphocytic 
stroma 'Warthin-like tumor' of the thyroid. Endocr Pathol 1998;9:317-323.

59 Chan JKC, Tsui MS, Tse CH. Diffuse sclerosing variant of papillary thyroid carcinoma. A histological and immunohistochemical study of three cases. Histopathology 1987;11:191-201.

60 Soares J, Limbert E, Sobrinho-Simoes M. Diffuse sclerosing variant of papillary thyroid carcinoma. A clinicopathologic study of 10 cases. Pathol Res Pract 1989;185:200-206.

61 Kwak JY, Kim EK, Hong SW, et al. Diffuse sclerosing variant of papillary carcinoma of the thyroid gland: specimen radiographic features with histopathological correlation. J Clin Endocrinol Metaab 2009;94:1491-1492.

62 Koo JS, Hong SH, Park CS. Diffuse sclerosing variant is a major subtype of papillary thyroid carcinoma in the young. Thyroid 2009;19:1225-1231.

63 Fukushima M, Ito Y, Hirokawa M, et al. Clinicopathologic characteristics and prognosis of diffuse sclerosing variant of papillary thyroid carcinoma in Japan: an 18-year experience at a single institution. World J Surg 2009;33:958-962.

64 Furmanchuk A, Averkin JI, Egloff B, et al. Pathomorphological findings in thyroid cancers of children from the Republic of Belarus: a study of 86 cases occurring between 1986 ('post-Chernobyl') and 1991. Histopathology 1992;21:401-408.

65 Nikiforov Y, Gnepp D, Fagin J. Thyroid lesions in children and adolescents after the Chernobyl disaster: implications for the study of radiation tumorigenesis. J Clin Endocrinol Metab 1996;81:9-14.

66 Volante M, Collini P, Nikiforov YE, et al. Poorly differentiated thyroid carcinoma: the Turin proposal for the use of uniform diagnostic criteria and an algorithmic diagnostic approach. Am J Surg Pathol 2007;31:1256-1264.

67 Nikiforov YE, Erickson LA, Nikiforova MN, et al. Solid variant of papillary thyroid carcinoma: incidence, clinical-pathologic characteristics, molecular analysis, and biologic behavior. Am J Surg Pathol 2001;25: 1478-1484.

68 Nikiforov Y, Gnepp DR. Pediatric thyroid cancer after the Chernobyl disaster. Pathomorphologic study of 84 cases (1991-1992) from the Republic of Belarus. Cancer 1994;74:748-766.

69 Collini P, Mattavelli F, Pellegrinelli A, et al. Papillary carcinoma of the thyroid gland of childhood and adolescence: morphologic subtypes, biologic behavior and prognosis: a clinicopathologic study of 42 sporadic cases treated at a single institution during a 30-year period. Am J Surg Pathol 2006;30:1420-1426.

70 Baloch ZW, LiVolsi VA. Follicular patterned lesion of the thyrid: the bane of the pathologist. Am J Clin Pathol 2002;117:141-150.

71 Williams ED, Abrosimov A, Bogdanova T, et al. Two proposals regarding the terminology of thyroid tumors. Intl J Surg Pathol 2002;8:181-183.

72 Baloch ZW, LiVolsi VA. Encapsulated follicular variant of papillary thyroid carcinoma with bone metastases. Mod Pathol 2000;13:861-865.

73 Rosai J. The encapsulated follicular variant of papillary thyroid carcinoma: back to the drawing board. Endocr Pathol 2010;21:7-11.

74 LiVolsi VA, Baloch ZW. The many faces of follicular variant of papillary thyroid carcinoma. Pathol Case Rev 2009;14:214-218.

75 Basolo F, Ugolini C, Proietti A, et al. Role of frozen section associated with intraoperative cytology in comparison to FNA and FS alone in the management of thyroid nodules. Eur J Surg Oncol 2007;33:769-775.

76 LiVolsi VA, Baloch ZW. Use and abuse of frozen section in the diagnosis of follicular thyroid lesions. Endocr Pathol 2005;16:285-293.

77 Hirokawa M, Carney JA, Goellner JR, et al. Observer variation of encapsulated follicular lesions of the thyroid gland. Am J Surg Pathol 2002;26:1508-1514.

78 Clary KM, Condel JL, Liu Y, et al. Interobserver variability in the fine needle aspiration biopsy diagnosis of follicular lesions of the thyroid gland. Acta Cytol 2005;49:378-382.

79 Elsheikh TM, Asa SL, Chan JK, et al. Interobserver and intraobserver variation among experts in the diagnosis of thyroid follicular lesions with borderline nuclear features of papillary carcinoma. Am J Clin Pathol 2008;130:736-744.

80 Sack MJ, Astengo-Osuna C, Lin BT, et al. HBME-1 immunostaining in thyroid fine-needle aspirations: a useful marker in the diagnosis of carcinoma. Mod Pathol 1997;10:668-674.

81 Beesley MF, McLaren KM. Cytokeratin 19 and galectin3 immunohistochemistry in the differential diagnosis of solitary thyroid nodules. Histopathology 2002:41:236-243.

82 Nikiforov YE. RET/PTC rearrangement in thyroid tumors. Endocr Pathol 2002;13:3-16.

83 Liu J, Singh B, Tallini G, et al. Follicular variant of papillary thyroid carcinoma: a clinicopathologic study of a problematic entity. Cancer 2006;107:1255-1264. 